\title{
The occurrence of multi-drug-resistant (MDR) Salmonella typhi in Southern Benue, Nigeria
} \author{
Godwin Attah Obande3 ${ }^{3}$ Oyiwona Emmanuel Godwin', Adejor Johnson ${ }^{4}$ \\ Biological Science Department, Benue State University, Makurdi, Nigeria \\ 2 Department of Microbiology, Federal University of Agriculture, Makurdi, Benue State, Nigeria \\ 3 Department of Microbiology, Federal University, Lafia, Nassarawa State, Nigeria \\ 4 Department of Science Laboratory Technology, Benue State Polytechnic, Ugbokolo, Nigeria
}

Peter Adikwu1 ${ }^{*}$, Ebele Uchenna Umeh², Innocent Okonkwo Ogbonna ${ }^{2}$, Charles Chidozie Iheukwumere²,

\begin{abstract}
Typhoid fever, whose causal agent is Salmonella typhi has high endemicity in developing countries. This study investigated the distribution of multidrug resistant $S$. typhi in Southern Benue, Nigeria. Stool samples were obtained from $583(57.0 \%)$ male and $439(43.0 \%)$ female patients presumptively diagnosed with typhoid fever in government hospitals within the study area. Isolation and identification of S.typhi followed standard cultural and biochemical procedures using a range of selective culture media. The Salmonella typhi isolates were subjected to antibiotic susceptibility test using the standard disc diffusion method (Kirby-Bauer), and results were interpreted using the criteria of the Clinical Laboratory Standards Institute. Chi-square and analysis of variance (ANOVA) were used to determine associations amongst variables were used to determine associations between variables at $95 \%$ confidence level. Isolates from Ohimini $(57.1 \%, \mathrm{n}=12)$ had the highest rate of multidrugresistant strains, while Agatu (13.7\%; $n=7)$ had the least. Age groups $>60, \leq 10$ and 21-30 exhibited high MDR rates of $50.0 \%, 32.8 \%$ and $30.8 \%$ respectively. Isolates from female patients, $(33.3 \%)$ had higher MDR rate than their male $(23.1 \%)$ counterparts. The results showed a statistically significant difference in the prevalence of MDR $S$. typhi in the various locations sampled. The rate of MDR $S$. typhi isolates demonstrated in this study is remarkable and of great concern.
\end{abstract}

\section{Keywords:}

Occurrence, Salmonella typhi, multi-drug, Resistance, Typhoid

\section{INTRODUCTION}

Multi-drug-resistant typhoid fever (MDRTF) is typhoid fever caused by $S$. typhi strains that are resistant to all the three first-line recommended drugs (chloramphenicol, ampicillin, and cotrimoxazole) used for its treatment ${ }^{1,2}$. Typhoid fever, otherwise known as enteric fever, is caused by Salmonella typhi, a Gram-negative, motile, non-spore forming, non-lactose forming, and facultative anaerobic, rod-shaped bacterium. The bacterium is solely a human pathogen with no known animal reservoir, and it is endemic in the world's tropical and sub-tropical regions ${ }^{3}$. It has developed into a significant public health problem in developing countries of the world, including Nigeria, where it constitutes a significant disease of morbidity and mortality ${ }^{4}$. Its estimated global annual incidence is 540 per 100,000 and 17 million cases worldwide 5 . Factors such as residence in a crowded household, contaminated water and food as well as poverty favour the spread of typhoid fever ${ }^{6}$.

Treatment of typhoid fever is mainly by antibiotic therapy. However, the emergence of multidrug resistance (MDR) has become a significant threat to public health ${ }^{3,7}$. Previous researchers have reported occurrence of MDR S. tyhpi strains in recent years in different parts of Nigeria and around the world ${ }^{3,8-10}$. The high rate of occurrence reported by these researchers is remarkable and of great concern.

*Corresponding author:

*Peter Adikwu adikwupeter@gmail.com

Pharmaceutical Sciences Asia (C) 2021 by

Faculty of Pharmacy, Mahidol University, Thailand is licensed under CC BY-NC-ND 4.0. To view a copy of this license, visit https:// www.creativecommons.org/licenses/by-nc-nd/4.0/ 
S. typhi has been reported to be resistant to amoxicillin/clavulanic acid, tetracycline, ciprofloxacin, ampicillin, ceftriaxone and cotrimoxazole ${ }^{7,9,11,12}$. This trend suggests that most patients that contract the emerging MDR strains of $S$. typhi will not respond to treatment adequately if placed on one of these drugs, and may lead to high rates of treatment failure as reported by Crump et al. ${ }^{13}$

The aim of this study, therefore, was to investigate the distribution of multi-drug-resistant $S$. typhi in Southern Benue, Nigeria.

\section{Materials and Methods}

\subsection{Study Area}

The study was conducted in Benue. The area lies within the Guinea Savannah region of Central Nigeria (Mid-belt region) and experiences a tropical climate with moderate rainfall estimated to average $1173 \mathrm{~mm}$. The season of rain is experienced from April to October while the dry season runs from November to March. It has a population of about $1307647^{14}$. Benue South has 9 Local Government Areas (LGAs) which are Ado, Agatu, Apa, Obi, Ogbadibo, Ohimini, Oju, Okpokwu and Otukpo.

\subsection{Ethical approval}

The Ethical Committee on Research of the Benue State Hospitals Management Board granted ethical approval for this study (No. HMB/OFF/215/ VOL.I/91).

\subsection{Study Population}

The study was hospital-based and was carried out among patients diagnosed with typhoid fever using Widal reaction. The protocol and purpose of the study were explained to the patients (in and out-patients), and demographic information was obtained from each patient through a structured questionnaire. Information such as their age, gender, place of residence as well their antibiotic treatment course were collected. Only patients who presented with febrile symptoms, had a significant Widal titre and gave consent for participation in the study were recruited. Patients who withheld their consent and had a negative titre from their Widal test were excluded from the study.

\subsection{Sample Collection}

A total of 1022 stool samples were collected from patients who attended Secondary Health centres within the 9 LGAs of Southern Benue and transported to the Microbiology laboratory of the Federal University of Agriculture Makurdi for examination and microbiological analysis. Samples were collected between August 2016 and July 2017 at various health centres.

\subsection{Isolation of Salmonella typhi}

Each sample was first inoculated into Selenite broth base (Oxoid, CM 0395) and incubated for 24 hours at $37^{\circ} \mathrm{C}$ for pre-enrichment. Loopfuls of the broth were then streaked onto Salmonella Shigella agar (Oxoid, CM 0099) and Xylose Lysine Deoxycholate agar (Oxoid, CM 0469). Inoculated plates were then incubated at $37^{\circ} \mathrm{C}$ for 24 hours; suspected colonies were further sub-cultured onto Bismuth Sulfite agar (Oxoid, CM 0201) to obtain pure cultures.

\subsection{Identification of the Isolates}

Colonies were identified using their morphological and biochemical characteristics. The shape, colour and elevation of the bacterial colony were observed visually. Gram reaction, motility, catalase, indole, oxidase, citrate utilization and Triple sugar iron tests were performed ${ }^{15-16}$.

\subsection{Antimicrobial Susceptibility Test}

Salmonella typhi isolates were subjected to antimicrobial susceptibility test using the standard disc diffusion method. Results were interpreted using the criteria of the Clinical Laboratory Standards Institute ${ }^{17,18}$. Overnight cultures of each $S$. typhi isolate were inoculated into a test tube containing $5 \mathrm{ml}$ of phosphate-buffered saline (PBS). The turbidity of each inoculum was adjusted to $0.5 \mathrm{McF}$ arland standard prepared by mixing given amounts of barium chloride and sulphuric acid.

The standardized culture was evenly spread over the entire surface of Mueller-Hinton agar (Oxoid, CM 0337) plates using a sterile swab stick. Sterile forceps was used to carefully pick and gently place the antibiotic discs of known concentrations on the dried, inoculated surface of the Mueller-Hinton agar plates. The discs were gently pressed onto the medium surface with sterilized forceps to ensure firm contact. The plates were incubated at $37{ }^{\circ} \mathrm{C}$ for at least 18 hours.

The antibiotic impregnated discs (Oxoid Ltd)

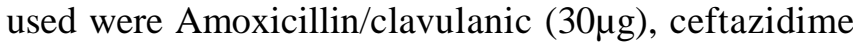
$(30 \mu \mathrm{g})$, ceftriaxone $(30 \mu \mathrm{g})$, amoxicillin $(10 \mu \mathrm{g})$, sulphamethoxazole/trimethoprim $(25 \mu \mathrm{g})$, chloramphenicol $(30 \mu \mathrm{g})$, ciprofloxacin $(5 \mu \mathrm{g})$, azithromycin $(15 \mu \mathrm{g})$, gentamycin $(30 \mu \mathrm{g})$ and imipenem $(10 \mu \mathrm{g})$. Diameters of zones of inhibition around the antibiotic disc were then measured to the nearest millimetre ${ }^{17-19}$.

\subsection{Data Analysis}


IBM SPSS Statistics version 21.0 (IBM Corp., Armonk, NY, USA) was used to analyze the results obtained. Associations between variables were determined by Pearson's chi-square test. The strength of the association between drug interaction and variables (location, age and gender) was also estimated using Pearson's chi-square test. A $P$ value less than or equal to 0.05 was interpreted to be statistically significant.

\section{RESULTS}

The distribution of multi-drug-resistant $S$. typhi, according to towns in the geographical zone was as shown in Figure 1. Isolates from Ohimini (57.1\%, $\mathrm{n}=12$ ) exhibited the highest rate of multidrug resistance within the geographical region, followed by Otukpo
(39.4\%; $\mathrm{n}=26$ ). Agatu had the least rate of MDR isolates $(13.7 \% ; n=7)$. The differences in the occurrence rate of MDR strains in the various LGAs within the Benue South geographical zone was statistically significant $\left(\chi^{2}=27.459, \mathrm{df}=8, p<0.05\right)$.

Distribution of MDR $S$. typhi with respect to age was as presented in Figure 2. Age group $>60, \leq 10$ and 21-30 years showed high MDR rates of $50.0 \%$, $32.8 \%$ and $30.8 \%$ respectively. The difference in the distribution of MDR $S$. typhi with respect to age was not statistically significant $\left(\chi^{2}=8.591, \mathrm{df}=6, p>0.05\right)$.

Table 1 presents the distribution of MDR $S$. typhi with respect to gender. Isolates from female patients (33.3\%) showed higher MDR rate than their male counterparts $(23.1 \%)$. The differences observed was statistically significant $\left(\chi^{2}=5.662, \mathrm{df}=1, p<0.05\right)$.

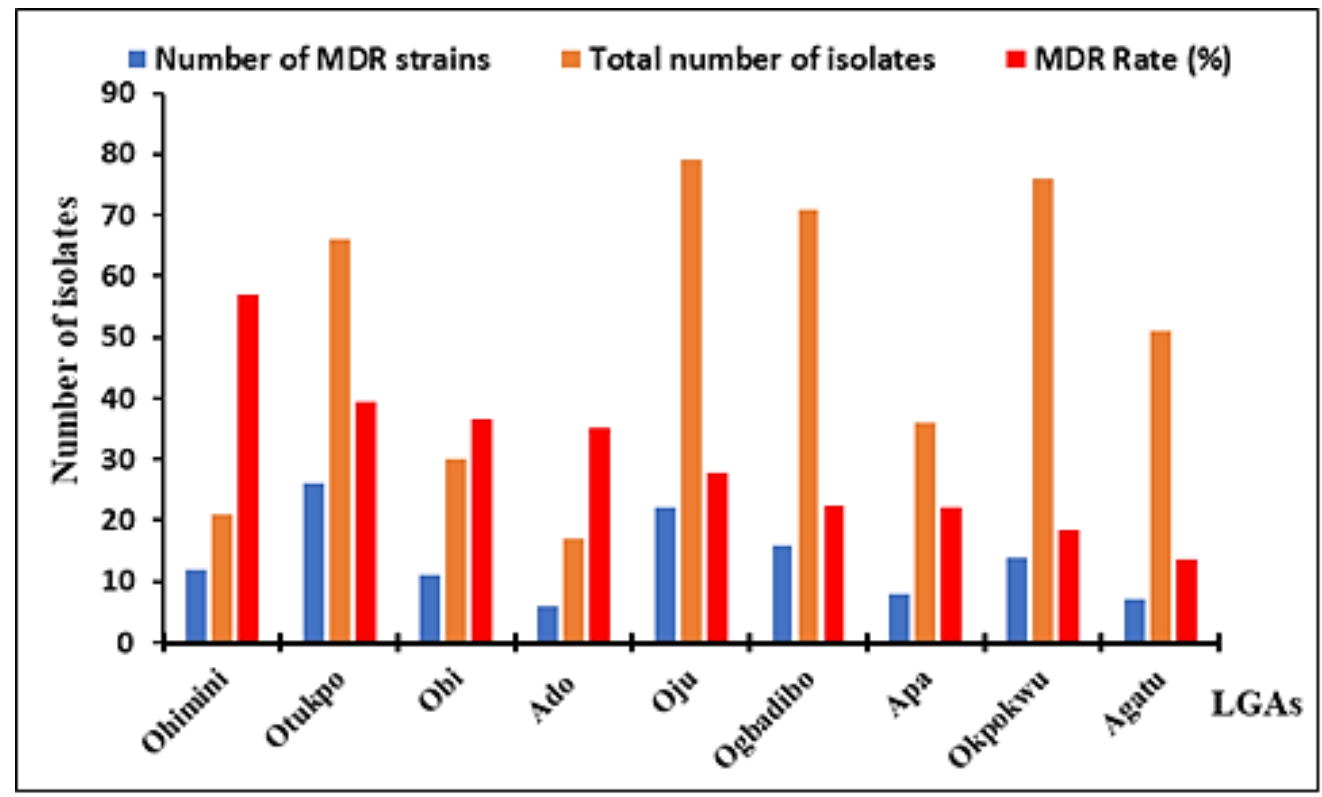

Figure 1. Occurrence of MDR S. typhi in Benue South geographical zone.

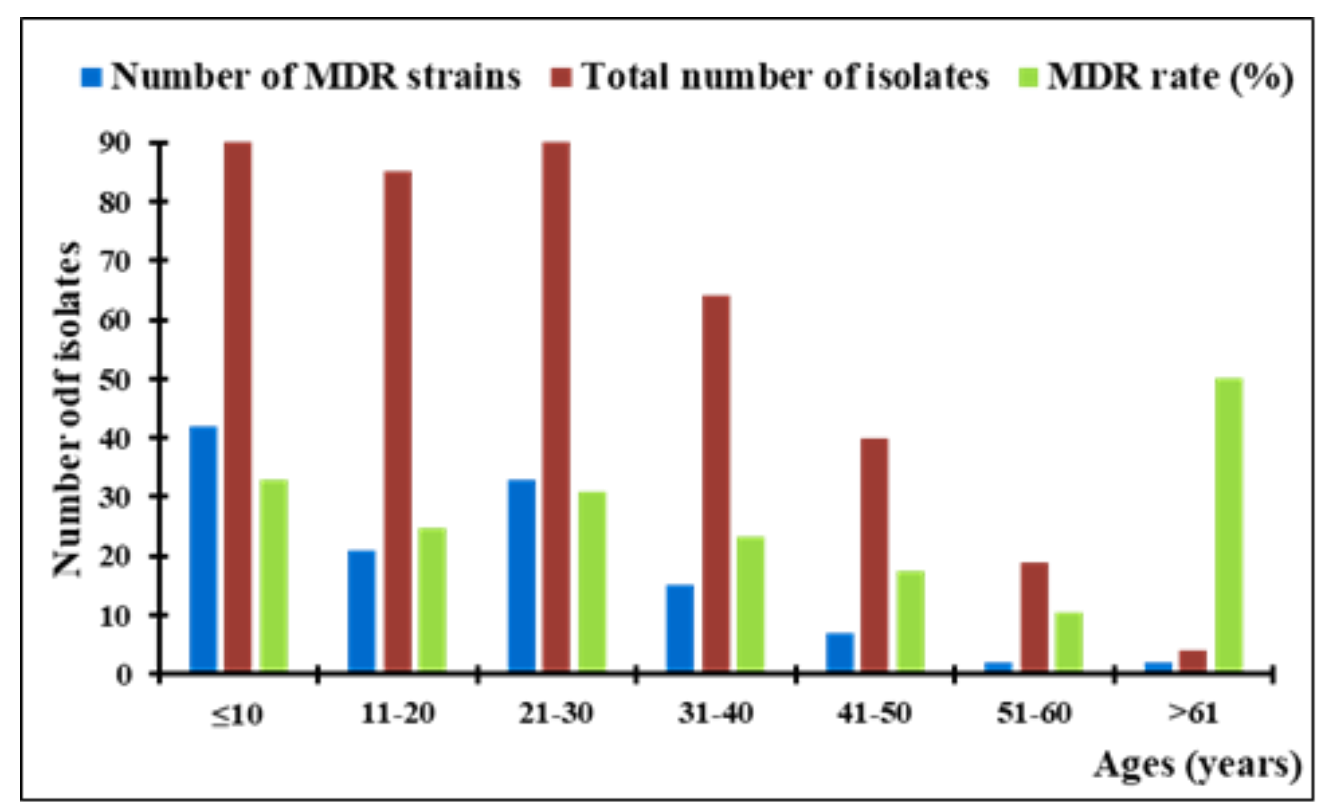

Figure 2. Occurrence of MDR S. typhi with respect to the age of patients. 
Table 1. Distribution of MDR S. typhi with respect to the gender of patients.

\begin{tabular}{lccc}
\hline Gender & Number of MDR strains & Total number of isolates & Rate (\%) \\
\hline Male & 64 & 273 & 23.1 \\
Female & 58 & 174 & 33.3 \\
Total & $\mathbf{1 2 2}$ & $\mathbf{4 4 7}$ & $\mathbf{2 7 . 1}$ \\
\hline
\end{tabular}

$\chi^{2}=5.662, \mathrm{df}=1, p=0.000(p<0.05)$

\section{DISCUSSION}

Multidrug resistance has been defined as resistance to at least one antibiotic in not less than 3 classes of antibiotics such as the quinolones, extendedspectrum cephalosporins, $\beta$-lactam/ $\beta$-lactamase inhibitor combinations, aminoglycosides and carbapenems ${ }^{20}$. This study reports a $27.3 \%$ multidrug resistance rate in $S$. typhi isolates from patients in Benue South geographical zone. A higher occurrence rate of MDR in S. typhi isolates was reported in Warri, Nigeria ${ }^{21}$, and Nepal ${ }^{2}$. The high prevalence of MDR S. typhi in Ohimini LGA and Otukpo could be attributed to the population density and poor access to health care facilities in these areas. The effect is the indiscriminate use of antibiotics occasioned by wrong prescription, the lack of access to quality healthcare, and the inadequate presence of qualified health personnel. A strong link between such a phenomenon and the development of resistance by pathogens to antibiotics has been established ${ }^{22}$. A lot of these local inhabitants may resort to self-help and selfprescription of over the counter antibiotics when ill, thereby abusing the use of antibiotics. Horizontal transfer of genetic elements which bear resistance is also a known source of resistance in pathogenic bacteria, including species of Salmonella ${ }^{23}$. Other mechanisms by which resistance is developed by Salmonella are drug inactivation, alteration of antibiotic target sites, the activity of efflux pumps and reduced permeability of membranes ${ }^{24,25}$.

Isolates from patients who were 60 years or older (50\%), and 10 years or younger (32.8\%) harboured more MDR $S$. typhi isolates than the other age groups. This agrees with the findings of Gupta et al. ${ }^{26}$ and Mannan et al. ${ }^{27}$, though they reported higher rates in the paediatric age group. The reason for this observed differences is not clear to us. We believe that aside the earlier mentioned role of indiscriminate antibiotic use, the faecal-oral route of transmission could be responsible for the transfer of resistant S. typhi.

Results of the study showed that the number of MDR strains was higher in females (33.3\%) than in males (23.1\%). Earlier findings of Gupta et al. ${ }^{26}$ and Mannan et al. ${ }^{27}$ however, were at variance with this present finding. They reported higher MDR strain presence in males than females. Our observation reveals that women in the geographical area are more involved in activities that may expose them to street foods which could harbour pathogenic bacteria. While the men are predominantly farmers, the women engage more in trading and sales of farm produces. Exposure to street foods has been linked with a higher possibility of contracting typhoid fever and hence, the causal agent ${ }^{28}$.

The rate of MDR demonstrated by $S$. typhi isolates especially in children and elderly patients in this study is remarkable and of great concern. Studies by Mandal et al. ${ }^{8}$, Kalu et al. ${ }^{29}$, Ehewarieme et al. ${ }^{21}$ and Harriet and Nandita $^{3}$ had reported an increased prevalence of multi-drug resistance around the globe. This finding suggests that most of the patients will not respond to treatment if placed on previously effective antibiotics. The implication is that patients are likely to have a prolonged fever clearance time and high rates of treatment failure ${ }^{13}$. The death rate of patients infected with antibiotic-resistant $S$. typhi is 21 times higher than individuals infected with non-antibiotic resistant strains $^{30,31}$. In addition, resistance to antibiotics by bacteria results in increased treatment costs, a burden which would be too heavy for people in the rural areas to bear. The rate of poverty in some of the study areas occasioned by weak economic status of the inhabitants, in addition to poor health facilities, makes quality healthcare far fetched. The findings of this study therefore makes it important for relevant authorities to pay attention to providing adequate healthcare infrastructure and trained, qualified personnel for health centers in sub-urban societies. This can greatly mitigate arbitrary use of antibiotics and reventually reduce resistance to antibiotics in such societies.

\section{CONCLUSION}

Results of this study showed that a high number of the $S$. typhi isolates exhibited multi-drug resistance (MDR). Isolates from females had higher MDR strains than isolates from males. The difference observed in the distribution of MDR strains within the different age groups was not statistically significant. The rate of multidrug resistance observed in $S$. typhi isolates in this study is remarkable and of great concern, considering the effect of the observed phenomenon on treatment outcome.

\section{ACKNOWLEDGMENT}

None to declare.

\section{Conflict of interest:}

The authors declare no conflict of interest. 


\section{Funding}

None to declare.

\section{Ethics approval}

The Ethical Committee on Research of the Benue State Hospitals Management Board granted ethical approval for this study (No. HMB/OFF/215/VOL.I/91).

\section{Article info:}

Received May 26, 2020

Received in revised form December 25, 2020

Accepted January 4, 2021

\section{REFERENCES}

1. Zaki SA, Karande S. Multidrug-resistant typhoid fever: a review. J Infect Dev Ctries. 2011;5(5):324-37.

2. Poudel S, Shrestha SK, Pradhan A, Sapkota B, Mahato M. Antimicrobial susceptibility pattern Salmonella enteric species in blood culture isolates. Clin Microbiol. 2014;3(2):342-9.

3. Harriet U, Nandita D. Mechanisms of Antibiotic resistance in Salmonella typhi. Int J Curr Microbiol Appl Sci. 2014;3(12): 461-76.

4. Ibekwe AC, Okonko IO, Onumkwo AU, Donbraye E, Babalola ET, Onoja BA. Baseline Salmonella agglutination titres in apparently healthy fishermen in Awka, South Eastern Nigeria. Sci Res Essays. 2008;3(9):225-30.

5. Qamar FN, Azmatullah A, Kazi AM, Khan E, Zaidi AK. A three-year review of antimicrobial resistance of Salmonella enterica serovars Typhi and Paratyphi A in Pakistan. J Infect Dev Ctries. 2014;8(8):981-6.

6. Kanj SS, Kanafani ZA, Shehab M, Sidani N, Baban T, Baltajian $\mathrm{K}$, et al. Epidemiology, clinical manifestations, and molecular typing of Salmonella typhi isolated from patients with typhoid fever in Lebanon. J Epidemiol Glob Health. 2015;5(2):159-65.

7. Sehra D, Sehra S, Ralia P, Sehra ST. An altered drug resistance pattern in Salmonella typhi. Am J Infect Dis Microbiol. 2013; 1(5):84-5.

8. Mandal S, Mandal MD, Pal NK. Plasmid-Encoded Multidrug Resistance of Salmonella typhi and some Enteric Bacteria in and around Kolkata, India: A Preliminary Study. Online J Health Allied Scs. 2004;3(4):4-8.

9. Ifeanyi CIC, Bassey EB, lkeneche NF, lsu RN, Akpa AC. Prevalence and Antimicrobial Susceptibility of Salmonella Species Associated with Childhood Acute Gastroenteritis in Federal Capital Territory Abuja, Nigeria. Br Microbiol Res J. 2013;3(3):431-9.

10. Mohammed SA, Tsaku PA, Nkene IH, Oti VB, Ekeleme K. Plasmid-mediated Resistance in Salmonella typhi Isolates from Door Handles in Nasarawa State, North-central Nigeria. Asian J Biotechnol Bioresour Technol. 2017;1(1):1-12.

11. El Kholy A, Baseem H, Hall GS, Procop GW, Longworth DL. Antimicrobial Resistance in Cairo, Egypt 1999-2000. A survey of five Hospitals. J Antimicrob Chemother. 2003;51(3):625-30.

12. Ishaleku D. Molecular characterization of antibiotic resistant Salmonella typhi and S. paratyphi isolates in Nassarawa State. Unpublished Ph.D. [dissertation]. Makurdi: University of Agriculture; 2015.

13. Crump JA, Ram PK, Gupta SK, Miller MA, Mintz ED. Analysis of data gaps pertaining to Salmonella enrerica serotype Typhi infections in low and medium human development index countries, 1984-2005. Epidemiol Infect. 2008;136(4):436-48.

14. National Population Commission. Federal Republic of Nigeria Official Gazette, Abuja. 2009;96(2):12-13.

15. Ochei JO, Kolhatkar A. Medical Laboratory Science and Practice. New York: Tata McGrew-Hill; 2008.

16. Arora DR, Arora B. A textbook of Microbiology. $3^{\text {rd }}$ ed. New Delhi: CBS publishers; 2011.

17. Clinical and Laboratory Standards Institute. Performance standards for antimicrobial disk susceptibility tests, $9^{\text {th }}$ ed. Approved standard M2-A9. Wayne, PA: Clinical and Laboratory Standards Institute; 2013.

18. Clinical and Laboratory Standards Institute. Performance Standards for Antimicrobial Susceptibility Testing; $25^{\text {th }}$ Informational Supplement. CLSI document M100-S25. Wayne, PA: Clinical and Laboratory Standards Institute; 2015.

19. Alaali Z, Bin Thani AS. Patterns of antimicrobial resistance observed in the Middle East: Environmental and health care retrospectives. Sci Total Environ. 2020;740:140089.

20. Lewis T, Loman NJ, Bingle L, Jumaa P, Weinstock GM, Mortiboy D, et al. High-throughput wholegenome sequencing to dissect the epidemiology of Acinetobacter baumannii isolates from a hospital outbreak. J Hosp Infect. 2010;75(1):37-41

21. Ehewarieme DA. Multidrug resistant Salmonellae isolated from blood culture samples of suspected typhoid patients in warri, Nigeria. Afri J Cln Exper Microbiol. 2011;12(2):58-61.

22. Ohanu ME, Iroezindu MO, Maduakor U, Onodugo OD, Gugnani HC. Typhoid fever among febrile Nigerian patients: Prevalence, diagnostic performance of the Widal test and antibiotic multi-drug resistance. Malawi Med J. 2019;31(3): 184-192.

23. Jaja IF, Bhembe NL, Green E, Oguttu J, Muchenje V. Molecular characterisation of antibiotic-resistant Salmonella enterica isolates recovered from meat in South Africa. Acta Trop. 2019;190:129-136.

24. Balasubramani G, Santhanam G, Nagarethinam B, Marudhamuthu M. Multidrug-resistant Salmonella: A raising calamity. Int J Res Pharm Sci. 2018;10(1):318-27.

25. Saxena K, Singh Y. Antimicrobial Resistance in Salmonella. J Basic Appl Sci. 2019;15(1):27-31.

26. Gupta V, Singla N, Bansal N, Kaistha N, Chander J. Trends in the antibiotic resistance patterns of enteric Fever isolates-a three year report from a tertiary care centre. Malays J Med Sci. 2013;20(4):71-5.

27. Mannan A, Shohel M, Rajia S, Mahmud NU, Kabir S, Hasan I. A cross sectional study on antibiotic resistance pattern of $S$. typhi clinical isolates from Bangladash. Asian Pac J Trop Biomed. 2014;4(4):306-11.

28. Shujat U, Ikram A, Hashmi IQJ, Abbasi SA, Afzal A, Ayyub M. Current antimicrobial sensitivity pattern of typhoidal salmonellae in a referral diagnostic centre. Microbiol Med. 2016;31(1):11-13.

29. Kalu 1G, Ogbulie TE, Opara FN. Pattern of multidrug resistant Salmonella enterica serovar Typhi isolates in Nigeria. Afr $\mathbf{J}$ Biotechnol. 2008;7(21):3817-20.

30. Kariuki S, Gilks C, Revathi G, Hart CA. Genotypic analysis of multidrug-resistant Salmonella enterica Serovar typhi, Kenya. Emerg Infect Dis. 2000;6(6):649-51.

31. Helms M, Vastrup P, Gerner-Smidt P, Mølbak K. Short and long term mortality associated with foodborne bacterial gastrointestinal infections: registry based study. BMJ. 2003;326(7385): 357. 